\title{
THE EFFECT OF MICRO-SILICA ON THE MICROSCOPIC FEATURES OF THE UHPC COMPOSITE AND ITS INTER-FACIAL TRANSITION ZONE
}

\author{
Vladimír Hrbek ${ }^{a, b, *}$, ZdenĚK ProšeK ${ }^{a}$, Roman ChylíK $^{a}$, LukÁŠ VRÁBlík ${ }^{a}$ \\ ${ }^{a}$ Czech Technical University in Prague, Faculty of Civil Engineering, Thákurova 7, 16629 Prague 6, Czech \\ Republic \\ ${ }^{b}$ Institute of Theoretical and Applied Mechanics AS CR, v.v.i., Prosecká 76, 19000 Prague 9, Czech Republic \\ * corresponding author: vladimir.hrbek@fsv.cvut.cz
}

\begin{abstract}
The uplift of concrete overall macroscopic performance by way of alternative additives is commonly used technique. In case of ultra high performance concrete (UHPC), micro-silica is added to the mixture as a micro-filler to the structure of cement binder. As a result, the cementitious matrix macro-mechanical performance is elevated. This paper is aimed on the UHPC micro-scale enhancement by different micro-silica additive content in the mixture. More closely, the study investigate the impact of the micro-silica on the inter-facial transition zone (ITZ) between the binder matrix and basaltic aggregate.
\end{abstract}

KEYWORDS: High performance concrete, indentation, spectral deconvolution SEM, image analysis, ITZ.

\section{INTRODUCTION}

The rise of high performance concrete (HPC) usage in civil engineering practice over last decades can be generally attributed to increasing demands on sustainable development and cost reduction of constructions and building materials. The HPC exceeds the properties and construct-ability of normal concrete. This can be obtained, besides special mixing, placing, and curing practices, by addition of special materials specially selected for the concrete to meet required performance or combination of few. One of such additives, used in high performance concrete design, is microsilica (or silica fume).

Microsilica, in terms of its chemical composition, is a very fine solid sphere-like mineral composed of silicon dioxide $\left(\mathrm{SiO}_{2}\right)$. Most silica fume particles are less than 1 micron in diameter. For example, average cement particle of CEM I 42.5R - Mokrá has $34 \mu \mathrm{m}$ in diameter and fly ash particles diameter ranges from 0.5 to $300 \mu \mathrm{m}[1-\underline{3}]$.

The silica fume is a by-product of the industrial manufacture of ferro-silicon and metallic-silicon in high-temperature electric arc furnaces. The ferrosilicon or silicon product is drawn off as a liquid from the bottom of the furnace. Vapor rising from the $2000{ }^{\circ} \mathrm{C}$ furnace bed is oxidized and, after cooling, the condensate of particles is collected. Processing the condensed fume to remove impurities and control particle size yields to microsilica production [4].

The effectiveness of silica fume as a pozzolan and a micro-filler depends on its composition and particle size, which are given by the design of the furnace and the composition of the raw charging materials of the furnace. Dosage of microsilica addition range used in concrete is typically in about 5 to $20 \%$ of cement weight, but up to 40 weight percentage can be found. Used as an admixture, microsilica can improve both fresh and hardened state properties of concrete [5, 6].

Most of current economic and environmental aspects favor the use of silica fume as an admixture, as growing body of studies of concrete with microsilica content shows improvement of its mechanical features, impermeability, chemical and abrasion resistance. From both micro-structural and mechanical angle, cement paste with silica fume containment comprise higher percentages of the calcium-silicate hydrates (CSH) and less of the soluble calcium hydroxides, compare to ordinary cement pastes. Because the microsilica particles size, its grains disperse in $\mathrm{CSH}$ gel, forming fine and uniform cementitious matrix with improved mechanical properties [7-10].

\section{Materials, SAMPLE PREPARATION}

Four different mixtures of cementitious specimens were selected for purpose of this study - referential mixture (REF) and 3 modified mixtures containing 10, 20 and 30 weight\% cement by mircosilica replacement (SF10, SF20 and SF30). Ingredients of referential mixture consisted of CEM I 42.5 R - Mokrá binder, aggregate filler (crushed unwashed basalt of particle sizes 0-4, 4-8 and 8-16 $\mathrm{mm}$ ), water and poly-carbonate based plasticizer (Stachement 508, Stachema). The compositions is described in Tab. 1 .

Macroscopic specimens, cubes of $100 \mathrm{~mm}$ in each dimension, were kept in laboratory water environment $\left(20-25^{\circ} \mathrm{C}\right)$ over 14 days for adequate composite matrix maturation and to reduction of rheological processes and specimen degradation. Furthermore, grinding 
and polishing methods avoiding selective abrasion of phases were implemented on epoxy-resin embedded cuts of samples for purpose of electron microscopy and indentation. Usage of these methods ensured both adequate roughness of the specimens surface and compact interface transition zone between aggregate and cementitious matrix.

\begin{tabular}{lcccc}
\hline Component & REF & SF10 & SF20 & SF30 \\
\hline CEM I 42.5 R & 800.0 & 720.0 & 640.0 & 560.0 \\
Aggreg. 0-4 & 730.0 & 730.0 & 730.0 & 730.0 \\
Aggreg. 4-8 & 390.0 & 390.0 & 390.0 & 390.0 \\
Aggreg. 8-16 & 320.0 & 320.0 & 320.0 & 320.0 \\
Microsilica & 0.00 & 80.0 & 160.0 & 240.0 \\
Water & 210.0 & 231.0 & 252.0 & 273.0 \\
Plasticizer & 32.0 & 36.0 & 36.0 & 36.0 \\
\hline
\end{tabular}

TABLE 1. Compositions of tested mixtures in $\left[\mathrm{kg} \cdot \mathrm{m}^{-3}\right]$.

\section{Methods And DATA PROCESSing}

The scanning electron microscopy (SEM) and grid nano-indentation testing were independently used to evaluate high performance concrete specimens. In order to overcome complex heterogeneity of the composite, both investigating methods were implemented on two main material levels, i.e. matrix without basaltic aggregate and transition zone between aggregate and matrix with limited clinker occurrence. Due to this separation, duplicity of obtained data (mechanical and/or structural features of different phases, such as aggregate and clinker) is prevented.

\subsection{SCANNING ELECTRON MICROSCOPY AND IMAGE ANALYSIS}

Scanning electron microscope Mira II LMU (Tescan corp., Brno) equipped with EPMA was used for microstructure investigation and phase recognition of HPC samples with silica fume content. Chemical composition (i.e. elemental analysis) of each phase was established by energy-dispersive X-ray spectroscopy (EDX). Despite precision of the EDX in determining weight percentage representation of each chemical element in measured area, time demands and coverage limitations of this method are not suitable for proper overall investigation of specimen structure.

In general, energy of back-scattered electron (BSE) and their brightness captured by BSE diagram is relevant to chemical composition of investigated compound. Therefore, combination of appropriate number (20 positions for each sample) of chemical composition and gray-scale range from EDX investigation and gray-scale SEM BSE diagrams image analysis led to numerical quantification of percentage representation of each phase, i.e. description of material structure (see Fig. 2). In case of aggregate-matrix transition zone, two-stage image analyses was applied on BSE diagrams as the sodium-calcium feldspar forming a structure of basalt aggregate is, on gray-scale, close to phases present in matrix. Differential image analysis thus consisted of separating main binding phases (C$\mathrm{S}-\mathrm{H}$ gel) and the rest of the material with following identification of these phases based on their internal heterogeneity.

\subsection{QUASI-STATIC INDENTATION AND SPECTRAL DECONVOLUTION}

Individual phases elastic micro-mechanical features were derived from grid indentation of prepared samples (Ti 700 series, Hysitron Inc.). Principle of indendentation technique is based on dependency of probe propagation with respect to the recorded material response. The force-displacement record is further processed and the mechanical properties are calculated from the unloading part of the record. To avoid incorporated errors during the measurement (creep, visco-elasticity of measured phases), appropriate test setup is neccessary [11 16].

The applied load function prescribed for each indent was displacement driven with maximum indentation depth of $150 \mathrm{~nm}$. For each material level, the displacement driven function consisted of loading and unloading period lasting 5 seconds with in-between holding time segment with 60 seconds duration, over which maximum indentation depth was held in order for material to creep. The indents, again for both levels of investigation, were formatted in 21 by 21 grind with mutual $10 \mu \mathrm{m}$ separation. Due to material level separation and selected loading function, grid indentation criteria of heterogeneous material are met [17 21].

Indentation modulus of individual phases, forming the structure of the composite, were derived from normalized histograms of the measured data by spectral deconvolution. The histograms are previously cleared from incorrectly measured data, caused by human error or environmental conditions. The process of spectral deconvolution, unlike statistical deconvolution, incorporates mutual interaction of phases with different stiffness, such as interacting low-stiffness LD C-S-H and any other phase (like high-stiffness clinker). Even though both investigated material levels of all samples were measured and processed separately, overall effective features were established from merged data. Maximum allowed divergence between structural percentage representation and derived mechanical features did not exceed $5.0 \%$.

\section{Results}

The results of previously described methods and data analysis are stated in this section. Mechanical features of individual phases, derived from normalized histograms of indentation measurements (Fig. 1) by spectral deconvolution, are summarized in Tab. 2.

The structural description of the composite, in means of individual phase percentage representa- 


\begin{tabular}{ccccllc}
\hline Sample & ITZ & LD CSH & HD CSH & \multicolumn{1}{c}{ Portlandite } & \multicolumn{1}{c}{ Clinker } & Aggregate \\
\hline REF & $13.68 \pm 2.38$ & $30.05 \pm 4.65$ & $38.93 \pm 2.47$ & $66.63 \pm 17.36$ & $120.54 \pm 17.99$ & $175.40 \pm 2.11$ \\
SF10 & $16.82 \pm 2.18$ & $32.91 \pm 4.16$ & $48.43 \pm 5.78$ & $66.55 \pm 8.50$ & $122.28 \pm 8.50$ & $159.58 \pm 8.22$ \\
SF20 & $18.47 \pm 2.41$ & $33.37 \pm 2.92$ & $48.94 \pm 4.24$ & $66.12 \pm 11.74$ & $135.49 \pm 11.74$ & $167.84 \pm 7.43$ \\
SF30 & $18.87 \pm 3.91$ & $34.70 \pm 3.17$ & $49.98 \pm 3.48$ & $65.82 \pm 6.51$ & $132.65 \pm 6.51$ & $168.47 \pm 14.02$ \\
\hline
\end{tabular}

TABLE 2. Indentation modulus $\mathrm{E}_{r}[\mathrm{GPa}]$ of concrete containing silica fume derived by spectral deconvolution.
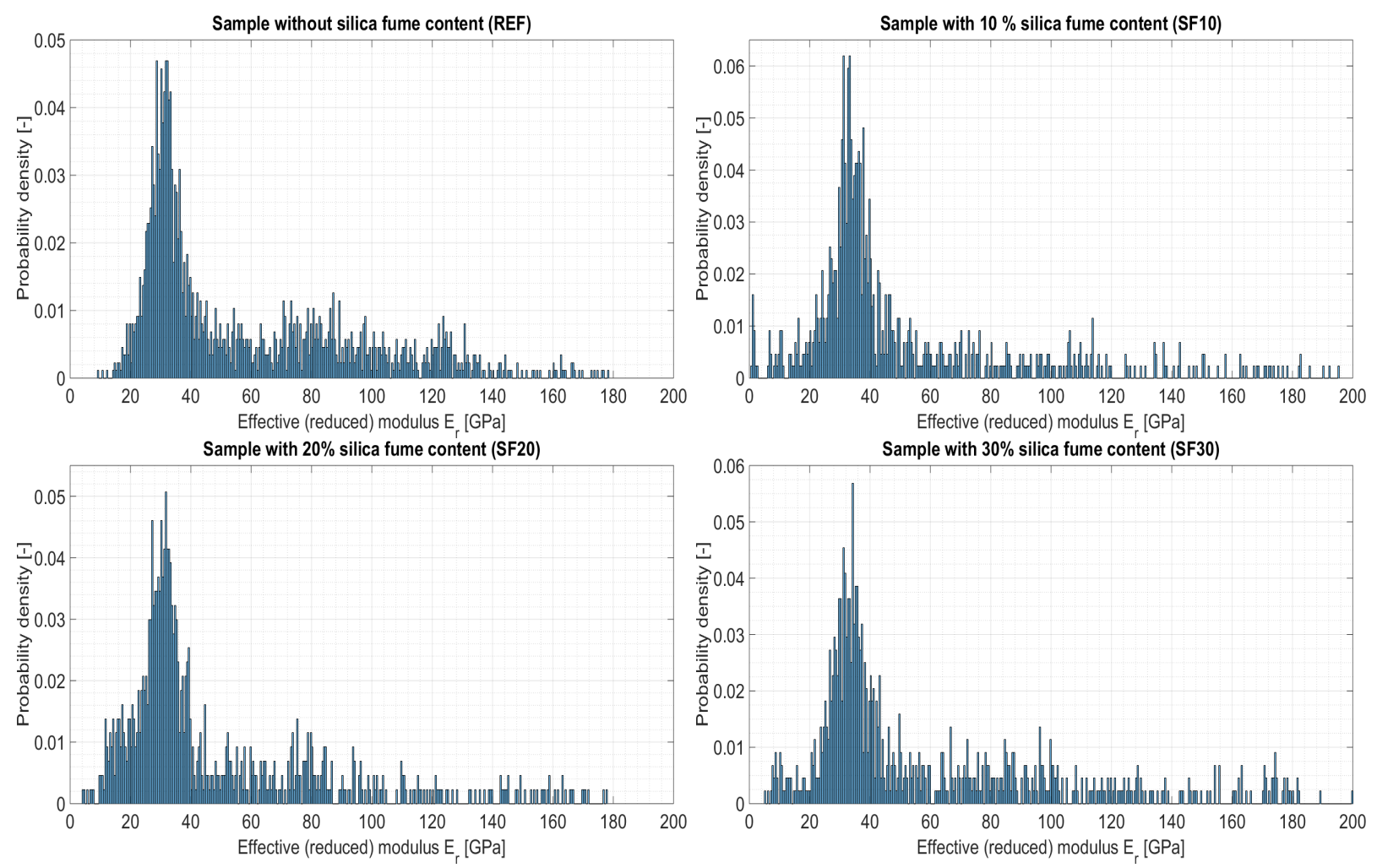

FiguRE 1. Histograms of indentation modulus $E_{r}$.

tion, acquired by image analysis of SEM BSE microdiagrams (Fig. 2), is shown in Tab. 3 .

\section{Conclusion}

From presented microscopical indentation results and phase representation (based on image analysis of SEM BSE diagrams) of investigated composites, following conclusions can be observed:

- indentation module of all main CSH phases (ITZ, LD CSH, HD CSH) are improved with silica fume content increment in specimens, while minor influence can be observed on calcium hydrate (portlandite) features;

- the highest impact can be observed on SF30 specimen, where indentation modulus of (compare to referential sample) inter-facial transition zone is increased by $37.9 \%$. The LD CSH and DH phases are enhanced by $15.5 \%$ and $28.4 \%$ respectively. The decrease of portlandite indentation modulus reaches $1.2 \%$;

- the microsilica content does not impact indenta- tion modulus of non-hydrated clinker and aggregate. The deviation of their micro-mechanical properties are caused purely by internal heterogeneity of these phases;

- the amount of silica fume addition and microporosity reduction are vice verse to impact on mechanical properties, i.e. SF10 sample (with the lowest percentage of microsilica additive) indicates minimum micro-porosity of the cement matrix $(22.7 \%$ of referential sample micro-porosity);

- comparison of SF30 sample to REF specimen shows that representations of LD CSH and non-hydrated clinker were increased by $22.2 \%$ and $61.7 \%$, while both HD CSH and calcium hydrate (portlandite) decreased by $12.3 \%$ and $13.9 \%$.

The impact of silica fume replacement for binder component of concrete composite on micro-structural aspect inter-facial transition zone was not conclusive. The gray-scale range (basic chemical composition) of the ITZ is identical low density CSH. Furthermore, detailed investigation of silica fume content impact on ITZ thickness, with respect to aggregate size, is 

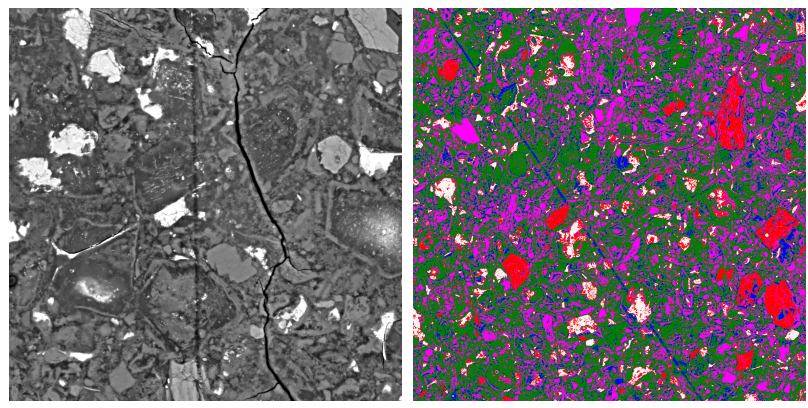

(A) . REF BSE diagram (left) image analyses (right).
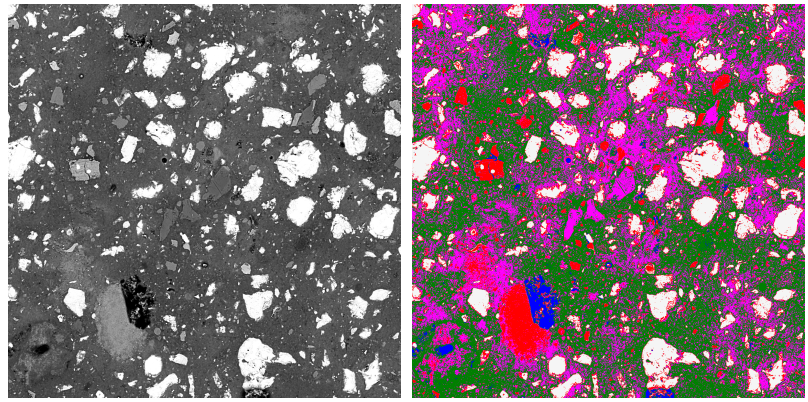

(C) . SF20 BSE diagram (left) image analyses (right).
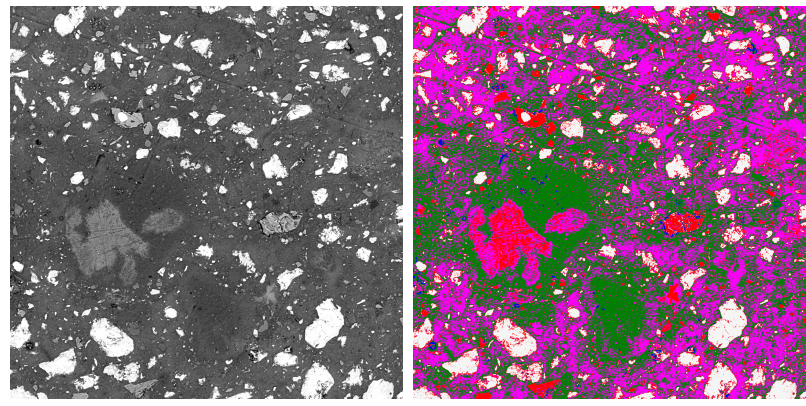

(в) . SF10 BSE diagram (left) image analyses (right).

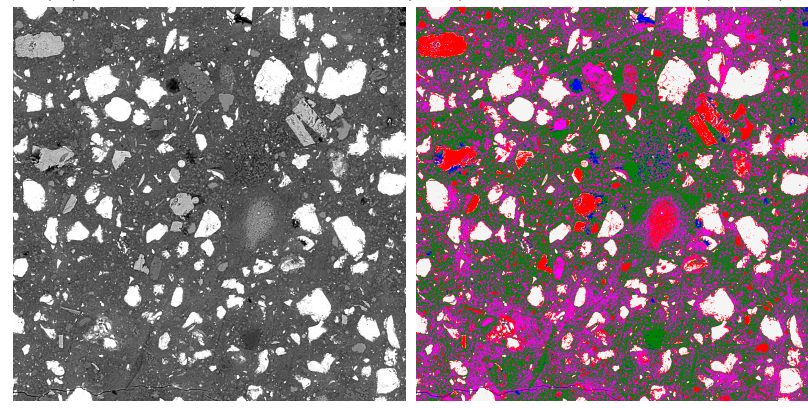

(D) . SF30 BSE diagram (left) image analyses (right).

Figure 2. Example of matrix analysis: white=clinker, red $=\mathrm{CH}$, magenta $=\mathrm{HD}$ CSH, green $=\mathrm{LD}$ CSH, blue=pores.

\begin{tabular}{ccccccc}
\hline Sample & Porosity & LD CSH & HD CSH & Portlandite & Clinker & Aggregate \\
\hline REF & $1.50 \pm 0.08$ & $15.82 \pm 1.25$ & $15.43 \pm 1.35$ & $6.55 \pm 0.55$ & $4.18 \pm 0.12$ & $56.52 \pm 2.39$ \\
SF10 & $0.34 \pm 0.02$ & $16.09 \pm 1.42$ & $16.61 \pm 1.44$ & $4.07 \pm 0.26$ & $5.43 \pm 0.56$ & $57.45 \pm 3.44$ \\
SF20 & $0.60 \pm 0.03$ & $18.30 \pm 1.98$ & $14.57 \pm 1.17$ & $4.49 \pm 0.32$ & $6.48 \pm 0.72$ & $55.56 \pm 4.31$ \\
SF30 & $1.09 \pm 0.09$ & $19.33 \pm 1.01$ & $13.74 \pm 1.38$ & $5.75 \pm 1.00$ & $6.76 \pm 0.65$ & $53.33 \pm 3.79$ \\
\hline
\end{tabular}

TABLE 3. Average percentage representation of individual composite phases.

proposed through line-indentation technique and SEM line-scan combination.

This research was done as a part of project concern with HPC additives (microsilica, fly ash and metakaolin) impact on the microscopic features of the composite. The data are be further used in numeric modeling of the material and predication of material elastic properties based on known mixture composition.

\section{LIST OF SYMBOLS \\ $F \quad$ Measured response/force $[\mu \mathrm{N}]$ \\ $h_{i}$ Indentation depth [nm] \\ $E_{r}$ Indentation modulus [GPa] \\ $H$ Hardness [GPa] \\ $h_{c}$ Contact depth [nm] \\ $P D$ Probability density $[-]$}

\section{ACKNOWLEDGEMENTS}

The research is financially supported by Czech Technical University in Prague - project SGS17/168/OHK1/3T/11 and by the Czech Science Foundation research project 17-19463S. The support is gratefully appreciated.

\section{REFERENCES}

[1] V. M. Malhotra, G. G. Carette. Silica fume - a pozzolan of new interest for use in some concrete. Concrete Construction 86(1):443-446, 1982.

[2] R. P. Khatri, V. Sirivivatnanon, W. Gross. Effect of different supplementary cementitious materials on mechanical properties of high performance concrete. Cement and Concrete Research 25(1):209-220, 1995. DOI:10.1016/0008-8846(94)00128-L

[3] A. Elahi, P. A. M. Basheer, S. V. Nanukuttan, Q. U. Z. Khan. Mechanical and durability properties of high performance concretes containing supplementary cementitious materials. Construction and Building Materials 24(3):292-299, 2010. DOI:10.1016/j.conbuildmat.2009.08.045

[4] V. M. Malhotra, G. G. Carette. Silica fume concrete properties, applications and limitations. Concrete International 5(5):40-46, 1983.

[5] V. Rahhal, et al. Calorimetry of portland cement with silica fume and gypsum additions. Journal of Thermal Analysis and Calorimetry 91(3):331-336, 2007. DOI:10.1007/s10973-005-7324-1

[6] W. Wongkeo, et al. Compressive strength and chloride resistance of self-compacting concrete containing high level fly ash and silica fume. Materials and Design 64:261-269, 2014. DOI:10.1016/j.matdes.2014.07.042 
[7] H. S. Shi, et al. Influence of mineral admixtures on compressive strength, gas permeability and carbonation of high performance concrete. Construction and Building Materials 23:1980-1985, 2009. DOI:10.1016/j.conbuildmat.2008.08.021

[8] A. A. Ramezanianpour, V. M. Malhotra. Effect of curing on the compressive strength, resistance to chloride-ion penetration and porosity of concretes incorporating slag, fly ash or silica fume. Cement and Concrete Composites 17(2):125-133, 1995. DOI:10.1016/0958-9465(95)00005-W

[9] M. J. Shannag. High strength concrete containing natural pozzolan and silica fume. Cement and Concrete Composites 22(6):399-406, 2000. DOI:10.1016/S0958-9465(00)00037-8

[10] M. I. Khan, R. Siddique. Utilization of silica fume in concrete: Review of durability properties. Resources, Conservation and Recycling 57:30-35, 2011. DOI:10.1016/j.resconrec.2011.09.016

[11] A. C. Fischer-Cripps. A simple phenomenological approach to nanoindentation creep. Journal of Material Science and Engineering A 385(1-2):74-82, 2004. DOI:10.1016/j.msea.2004.04.070

[12] J. Woirgard, J. C. Dargenton. An alternative method for penetration depth determination in nanoindentation measurement. Journal of Material Research 12(9):2455-2458, 1997. DOI:10.1557/JMR.1997.0324

[13] J. L. Hay, G. M. Pharr. Asm handbook volume 8: Mechanical testing and evaluation. 10th edition pp. 232-243, 2000.

[14] W. Oliver, G. M. Pharrr. An improved technique for determining hardness and elastic modulus using load and displacement sensing indentation measurements. Journal of Material Research 7(6):1564-1583, 1992. DOI:10.1557/JMR.1992.1564
[15] G. M. Pharrr, A. Bolshakov. Understanding nanoindentation unloading curves. Journal of Material Research 17(10):2660-2671, 2002. DOI:10.1557/JMR.2002.0386

[16] W. Oliver, G. M. Pharrr. Measuring of hardness and elastic modulus by instrumented indentation: Advances in understanding and refinement of methodology. Journal of Material Research 19(1):3-20, 2004. DOI:10.1557/jmr.2004.19.1.3

[17] L. Sorelli, G. Constantinides, F.-J. Ulm, F. Toutlemonde. The nano-mechanical signature of ultra high performance concrete by statistical nanoindentation techniques. Cement and Concrete Research 38(12):14471456, 2008. DOI:10.1016/j.cemconres.2008.09.002.

[18] F.-J. Ulm, M. Vandamme, C. Bobko, et al. Statistical indentation techniques for hydrated nanocomposites: Concrete, bone and shale. Journal of the American Ceramic Society 90(9):2677-2692, 2007. DOI:10.1111/j.1551-2916.2007.02012.x.

[19] G. Constantinides, K. S. Ravi Chandran, F.-J. Ulm, K. J. Van Vliet. Grid indentation analysis of composite microstructure and mechanics: Principles and validation. Journal of Material Science and Engineering A 430(12):189-202, 2006. DOI:10.1016/j.msea.2006.05.125

[20] W. Zhu, J. J. Hughes, N. Bicanic, C. J. Pearce. Nanoindentation mapping of mechanical properties of cement paste and natural rocks. Materials Characterization 58(11-12):1189-1198, 2007. DOI:10.1016/j.matchar.2007.05.018

[21] O. Bernard, F.-J. Ulm, E. Lemarchand. A multiscale micromechanics -hydration model for the early-age elastic properties of cement-based materials. Cement and Concrete Research 33(9):1293-1309, 2003. DOI:10.1016/S0008-8846(03)00039-5 